Síntese - Rev. de Filosofia

v. 37 N. 119 (2010): 351-370

\title{
A CONCEPÇÃo de ÉTICA E DIRETTO NA FILOSOFIA DE KANT
}

\author{
(The conception of Ethics and Right in Kant's philosophy)
}

\author{
Manfredo Araújo de Oliveira *
}

Resumo: $\mathrm{O}$ artigo procura em primeiro lugar situar o tratamento dado por Kant à problemática da ética e do direito dentro do contexto de quadro teórico da filosofia transcendental em contraposição às posturas hoje hegemônicas. Neste quadro teórico, a esfera do prático diz respeito, então, a tudo o que é possível através da liberdade. Aqui na autonomia da razão pura prática se situa para ele o único fundamento da normatividade e de seu conhecimento por nós. É precisamente enquanto sujeito da lei moral que o homem tem valor absoluto, ou seja, enquanto ele é ser livre e é precisamente a liberdade que o distingue de todos os outros seres. A realização da liberdade na esfera da exterioridade é o que Kant chama de legalidade, a esfera do direito, que, assim, em seu cerne, consiste na unificação de liberdade e natureza.

Palavras-chave: Autonomia da razão, normatividade, legalidade, liberdade e natureza.

Abstract: The present article firstly aims to situate the treatment Kant gives to the issue of ethics and of right within the theoretical context of transcendental philosophy in contrast to today's hegemonic stances. Within this theoretical framework, the sphere of practice thus concerns everything that is possible through freedom. For Kant, the autonomy of the pure practical reason is the

\footnotetext{
* Doutor em Filosofia pela Universität München Ludwig Maximilian, Alemanha, professor titular do Departamento de Filosofia da Universidade Federal do Ceará. Artigo submetido a avaliação no dia 20/04/2009 e aprovado para publicação no dia 29/07/2009.
} 
sole foundation of normativity and of our knowledge of it. It is exactly when man is the subject of moral law that he has absolute value, i.e when he is a free being, since it is precisely freedom that distinguishes him from other beings. The realization of freedom in the sphere of exteriority is what the author calls legality, the sphere of right which, in its core, consists in the unification of freedom and nature.

Keywords: Autonomy of reason, normativity, legality, freedom and nature.

Introdução

\section{O quadro teórico da Filosofia transcendental}

K

ant articula a problemática do debate sobre ética e direito que ocor ria desde o início da modernidade no quadro teórico de uma filo sofia transcendental ${ }^{1}$. Logo no prefácio à Crítica da Razão Pura (KrV B XVI, XVII), ele distingue sua posição do que considera a postura da tradição na medida em que para ele esta defendia a tese de que todo nosso conhecimento se guia de acordo com o objeto, uma posição que conduz a posicionamentos teóricos insustentáveis. A partir daqui ele articula sua própria proposta: os objetos é que se guiam de acordo com nosso conhecimento, ou seja, se todo conhecimento é compreender algo, então a tese fundamental aqui é que tudo o que é formalmente necessário para compreender algo vem da própria esfera do compreender ( $\mathrm{KrV}$ B 741,742/ A 713,714 e ss) e não da coisa compreendida.

Esta mudança de orientação ocorrida no pensamento de Kant significa o que E. Tugendhat ${ }^{2}$ chamou de "revolução reflexiva" do pensamento: tarefa da filosofia ${ }^{3}$ não é mais articular uma teoria do mundo ou de suas partes, o que é o objetivo específico das ciências, mas articular-se enquanto teoria da possibilidade e da validade de nosso conhecimento dos fenômenos do mundo e das normas de nossa ação através do retorno às estruturas do aparato cognitivo de nossa subjetividade (sensibilidade e entendimento

${ }^{1}$ Cf. HÖSLE V., Grösse und Grenzen von Kants praktischer Philosophie, in: Praktische Philosophie in der modernen Welt, München: Beck, 1992, p.20-21.

${ }^{2}$ Cf. TUGENDHAT E, Vorlesungen zur Einführung in die sprachanalytische Philosophie, Frankfurt am Main: Suhrkamp, 1976, p. 13-23.

${ }^{3}$ Cf. ALLISON H. E., Idealism and Freedom: essays on Kant's theoretical and pratical philosophy, Cambridge: Cambridge University Press, 1996. 
(conhecimento) e razão ${ }^{4}$ (ação). Consequentemente o conhecimento filosófico é um conhecimento inteiramente liberado de tudo o que é empírico ${ }^{5}$ e é uma atividade teórica que se distingue fundamentalmente de outras atividades teóricas como a atividade teórica das ciências empíricas e da matemática na medida em que sua tarefa é demonstrar a esfera de mediação do sujeito através de que conhecemos todo e qualquer objeto. Isto implica que seu método não pode ser idêntico ao destas outras atividades teóricas.

A filosofia transcendental se caracteriza, então, por ser uma investigação sobre a natureza dos instrumentos do conhecimento que se faz através de uma análise do aparato cognitivo humano para avaliar a amplitude de seu entendimento $^{6}$. Esta proposta teórica vai produzir uma reviravolta na tradição metafísica: aquilo que constitui o objeto central de sua investigação, ou seja, a questão do fundamento, dos princípios e das categorias, vai retornar aqui sob uma ótica epistemológica. Essas entidades passam a ser agora conceituadas não como dimensões do ser, mas como estruturas do aparato cognitivo humano que possibilitam a cognoscibilidade dos dados empíricos.

Esta análise levou Kant à afirmação de que somente através das categorias de nosso entendimento é constituído validamente através de nossos juízos ${ }^{7}$ como objeto universal o que nos é sensivelmente dado. Isto lhe permite dizer que o entendimento prescreve leis à natureza (Krv B 134), ou seja, as leis existem não nos fenômenos, mas somente em relação ao sujeito em que inerem os fenômenos, cujo ponto supremo é o entendimento (Krv B 164). A filosofia continua saber metafísico, apriórico, só que agora a

\footnotetext{
${ }^{4}$ Cf. HECK J. N., Da Razão prática ao Kant tardio, Porto Alegre: Edipucrs, 2007, p. 150: "Submetidos tão-somente às leis da mera razão, aos humanos não cabe mais o amparo moral do absolutismo teológico ou do teleologismo jusnaturalista”....

${ }^{5}$ Cf. ALMEIDA G. A. de, O conceito kantiano de Filosofia e a Fundamentação da Metafísica dos Costumes, in: PERES D. T. e outros (orgs.), Tensões e Passagens. Filosofia Crítica e Modernidade. Uma homenagem a Ricardo Terra, São Paulo: Singular/Esfera Pública, 2008, p. 49: “.... Kant deixa claro que os conceitos tematizados na Filosofia não são produzidos pelo filósofo ele próprio, mas são conceitos produzidos pela razão humana comum e sobre os quais o filósofo reflete, a fim de saber o que podemos conhecer a partir deles acerca dos objetos da razão em geral".

${ }^{6}$ Cf. SANTOS, L. H. L., A essência da proposição e a essência do mundo, in: Wittgenstein, L. Tractatus Logico-Philosophicus. (Ed. Santos, L. H. L.) São Paulo: EDUSP, 1993, p.14: "A tarefa é investigar a natureza dos instrumentos do conhecimento a fim de determinar se as pretensões da filosofia, no que elas excedem qualitativamente as da investigação empírica da realidade, são ou não legítimas. Estas pretensões são fundamentalmente as que definem a chamada metafísica”.

${ }^{7}$ Cf. BARBOSA FILHO B., Sobre uma crítica da razão jurídica, in: PERES D. T. e outros (orgs.), Tensões e Passagens, op. Cit., p. 13: "Para começar, Kant restaura a natureza proposicional ou judicativa (isto é, não-representacional) do saber e o do pensamento. Se há conhecimento, há juízo e há juízo apenas se há intuição e conceito".
}

Síntese, Belo Horizonte, v. 37, n. 119, 2010 
transcendência não se faz na direção do princípio absoluto de todo ser, mas na direção da subjetividade humana enquanto conjunto das condições de possibilidade da objetificação dos dados de nossa sensibilidade. A experiência, portanto, não pode ocorrer sem a mediação das categorias de nosso pensamento.

Esta leitura transcendental do conhecimento justifica o empreendimento das ciências modernas, pois a ciência só pode ser universal e necessária, como é sua pretensão, se ela tiver um fundamento a priori uma vez que na experiência mesma nada existe de necessário. Deste modo, tal fundamento a priori só é possível se vier da subjetividade. Já que se trata de um a priori subjetivo, não é possível captar a verdadeira realidade, a realidade numenal, que subjaz à realidade fenomenal descrita pela ciência. Por esta razão as categorias de nosso entendimento não podem ser aplicadas a esta realidade numenal. Assim se pressupõe aqui uma ontologia com dois níveis de ser: o fenomênico e o numênico sendo que o numênico não é captável por nós, ele está para além ou fora de nossa rede conceitual, mas tem que ser postulado para que possamos compreender nosso conhecimento dos fenômenos.

Na filosofia prática ${ }^{8}$, transcendentalmente articulada, Kant se situa em posição radicalmente contraposta à mentalidade hoje vigente. Uma objeção que põe em questão a racionalidade da dimensão normativa tanto ética como jurídica foi articulada no século passado pelo positivismo lógico e depois retomada pelas diferentes formas de decisionismo ${ }^{9}$ tem como tese básica que as questões relativas à razão prática não são suscetíveis de verdade, ou seja, às sentenças normativas, éticas ou jurídicas, não cabe a alternativa verdadeiro/ falso. Normas se legitimam por decisões que podem ser vinculadas numa série de tal forma que tudo desemboca numa decisão última sem que ela mesma possa ter legitimidade por algo além da própria decisão. $\mathrm{O}$ máximo que se pode fazer aqui é provar ${ }^{10}$ a consistência lógica do sistema de referências condicionantes das decisões e a capacidade de realização empírica dos fins estabelecidos de acordo com os critérios de valor que foram assumidos pelas decisões tomadas.

Certamente é possível formular sentenças descritivas sobre normas assim, por exemplo, quando falo sobre os direitos humanos presentes na constituição brasileira: trata-se aqui simplesmente de sentenças não-normativas sobre normas e valores enquanto uma investigação empírica sobre siste-

${ }^{8}$ Cf. ROHDEN V., Razão prática e direito, in: ROHDEN V. (org.), Racionalidade e ação, Porto Alegre: Goethe Institut, 1997.

${ }^{9}$ A respeito do exemplo de C. Schmitt cf. ARRUDA J. M., Carl Schmitt: política, Estado e direito, in: OLIVEIRA M./ AGUIAR O. A./ Andrade e Silva SAHD L. F. N (org.), Filosofia Política contemporânea, Petrópolis: Vozes, 2003, p. 56-86.

${ }^{10}$ Cf. a respeito: FERRAZ Jr. T. S., A legitimidade pragmática dos sistemas normativos, in: MERLE J-Chr./ MOREIRA L. (org.), Direito e Legitimidade, São Paulo: Landy, 2003, p. 289 e ss. 
mas dados de normas o que exige a distinção clara entre sentenças sobre normas no sentido de uma investigação sobre sua vigência empírica em determinados contextos sociais, e sentenças que levantam a pretensão de ser normativamente válidas. A postura decisionista não reconhece propriamente validade normativa: normas podem ser descritas e explicadas, mas não podem ser legitimadas.

Em contraposição radical à postura kantiana se põe também o relativismo contemporâneo que assume a forma de contextualismo e particularismo. Podemos com Kersting afirmar a que a tese central de uma postura relativista consiste em considerar os sistemas morais como dotados de uma validade apenas relativa "não podendo, por conseguinte, reivindicar uma validade universal, validade supratemporal e invariável, de cultura para cultura ${ }^{11 "}$. A partir daqui, toda tentativa de fundamentar uma postura normativa universalista, como é o caso da filosofia prática de Kant, se baseia numa "ilusão arquimédica" já que é impossível ao ser humano se subtrair aos quadros conceituais de seu próprio contexto cultural ${ }^{12}$. Numa palavra, as normas éticas e jurídicas não possuem fundamento objetivo e só podem existir como mero ordenamento social a partir de consensos estritamente convencionais, portanto, arbitrários, mera regra de jogo ${ }^{13}$.

Um bom exemplo deste tipo de contextualismo radical é Rorty. O pensamento clássico pretendeu, segundo Rorty, através do conceito, expressar a forma e o movimento da natureza e da história. Esta pretensão em última instância levou o pensamento tradicional à ambição de descobrir com segurança como eliminar a injustiça da história humana ${ }^{14}$. A partir da intuição exatamente contrária Rorty julga que se trata aqui precisamente da doença que contamina todo o pensamento ocidental. Não existe uma realidade maior, como é a convicção básica da filosofia ocidental, para além da realidade que se revela na experiência no dia-a-dia capaz de oferecer um horizonte de reconciliação e salvação para a ação do ser humano no mundo. Por esta razão sua proposta consiste basicamente em curar a humanidade da doença platônica, metafísica, o que, segundo ele, deve ocor-

\footnotetext{
${ }^{11}$ Cf. KERSTING W., Em defesa de um universalismo sóbrio, in: Universalismo e Direitos Humanos, Porto Alegre: Edipucrs, 2003, p. 82.; Wohlgeordnete Freiheit. Immanuel Kants Rechts und Staatsphilosophie, Berlin/ New York: de Gruyter, 1984.

${ }^{12}$ Cf. KERSTING W., op. cit. (2003), p. 83: "O relativista assevera, portanto, não só que todo o sistema de convicções morais se desenvolveu historicamente e possui um destino cultural; ele afirma também que, em princípio, é impossível, dentro do sistema de convicções morais historicamente formado, encontrar-se uma área de regras, um segmento de normas que não mostrasse vestígios da história de seu surgimento".

${ }^{13}$ Cf. KERSTING W., op. cit., p. 84: "Se não há princípios morais de validade universal, que comprometem de igual maneira cada pessoa, independentemente de sua situação de vida, então é claro que também não se podem encontrar regras normativas para organizar a interação dessas diferentes esferas culturais”.

${ }^{14}$ Cf. RORTY R., Objectivity, Relativism and Truth, Philosophical Papers I, Cambridge: Cambridge University Press, 1991.
} 
rer teoricamente através de uma radicalização da postura da filosofia analítica que tem seu cerne na reviravolta lingüística ${ }^{15}$.

Na medida em que esta reviravolta é levada até o fim por meio da reviravolta pragmática se apresenta a urgência do abandono de um pressuposto que a conectou veladamente à grande tradição do pensamento ocidental, ou seja, a de que ainda há verdades filosóficas a descobrir e que elas podem ser argumentativamente legitimadas. Daí sua conclusão: a primeira tarefa da filosofia hoje é a desconstrução da metafísica, o desmascaramento do platonismo, que inicia com a demonstração de que mesmo a filosofia analítica se manteve prisioneira da metafísica que contestou o que revela o fato de que toda nossa cultura se radica em mal-entendidos que remontam a Platão.

Ora, o objetivo fundamental que Kant se propõe é justamente fundamentar os valores e as normas básicas na própria razão ${ }^{16}$ e não em fatos sociais como, por exemplo, as tradições ${ }^{17}$ o que significa dizer que nenhuma grandeza empírica pode fornecer o critério de validade das normas morais. Daí sua convicção de que o mundo apresentado pelas ciências da natureza não é o único mundo real uma vez que neste mundo só há fatos e não há valores e normas. A existência de uma ética objetiva exige uma ontologia que transcende o puramente fático e empírico.

\section{1) O Lugar sistemático da consideração da Ética: A Razão Pura Prática}

O ser humano, enquanto ser fenomenal, é inserido na série das causas fenomenais e enquanto tal é um ser determinado. Neste contexto Kant levanta a questão se esta afirmação não implica que o ser humano seja completamente subordinado ao determinismo natural ${ }^{18}$ uma vez que todo evento no mundo natural é inteiramente determinado por leis universais e necessárias. Já na Crítica da Razão Pura Kant havia apontado para a

\footnotetext{
${ }^{15}$ Cf. RORTY R., The linguistic Turn. Recent Essays in Philosophical Method, Chicago: University of Chicago Press, Phoenix Edition, 1970.

${ }^{16}$ A respeito do debate sobre o caráter transcendental da filosofia prática de Kant cf. HÖFFE O., Transzendentale oder vernunftkritische Ethik (Kant?). Zur Methodenkomplexität einer sachgerechten Moralphilosophie, in: Dialectica 35 (1981)195211. HECK J. N., Moral e Direito Racional, um estudo comparativo entre Kant, Hobbes e Rousseau, in: Síntese Nova Fase, v.25, n. 82 (1998)370-377. HERB L., Kants kritisches Staatsrecht, in: Jahrbuch für Recht und Ethik, vol. 2 (1994)431-478.

${ }^{17}$ Cf. HÖSLE V., Grösse und Grenzen, op. cit., p. 19.

${ }^{18} \mathrm{Cf}$. KLEMME H. F., A discreta antinomia da razão pura prática de Kant na Metafísica dos costumes, in: Cadernos de Filosofia Alemã XI (2008)13: “... dentre todos os seres vivos que existem no espaço e no tempo, só o homem, como ser espontâneo e de ação livre, pode se retirar do curso mecânico de uma natureza que é cega em relação à diferença entre os animais irracionais e o homem dotado de razão".
} 
possibilidade de uma ação ultrapassar a série das causas fenomenais ${ }^{19}$ que exibem sua força causal sobre a vontade humana de acordo com as leis mecânicas da natureza e partir espontaneamente do próprio ser humano. Isto significa afirmar que o ser humano enquanto ser numenal é portador da capacidade de iniciar por si mesmo uma ação originária que seja capaz de se sobrepor aos motivos causais que são provenientes de sua natureza e cujos efeitos se vão apresentar no mundo dos fenômenos.

O desfecho destas reflexões é a distinção entre dois tipos de causalidade em nosso agir: a causalidade empírica (do mundo dos fenômenos) e a causalidade inteligível (do mundo numenal, própria à liberdade). Toda causalidade implica uma lei, em virtude da qual seu efeito deve ser posto. Se há uma causalidade da liberdade, então, uma vez que ela é independente de toda lei natural, sua lei só pode ser instaurada por ela mesma. É precisamente isto que Kant denomina vontade: só um ser racional possui a capacidade de ser movido pela razão, ou seja, de agir segundo a representação de leis, portanto, segundo princípios e é nesse sentido que só ele tem vontade. Isto significa que exclusivamente no agir humano a ação é determinável por fins universais o que a distingue do puro arbítrio que põe seus fins singulares acima de tudo. Kant denomina essa causalidade "espontaneidade absoluta" e "incausada" ( $\mathrm{KrV}$ B 474, A 446), que inicia por si mesma uma série de fenômenos, estes,então, subordinados às leis naturais.

Portanto, a vontade é o tipo de causalidade que marca os seres vivos enquanto são racionais ${ }^{20}$ e justamente a liberdade é a propriedade deste tipo de causalidade uma vez que ela possui a capacidade de agir com independência frente a causas estranhas que a determinem e, assim, retirar-se parcialmente do mecanismo natural de determinação dando-se a si mesma uma lei. Desta forma, pode-se falar aqui estritamente de vontade autônoma precisamente porque ela é lei para si mesma (GMS BA 97,98). Assim, para Kant é fundamental distinguir entre uma causalidade segundo a natureza e uma causalidade segundo a liberdade ${ }^{21}$. $\mathrm{O}$ ato de espontaneidade não é um acontecimento, propriamente falando, uma vez que sua causalidade está fora das leis da natureza e por isso não pode ser determinada pela experiência, "transcende" a experiência. Assim, o absolutamente incondicionado não é encontrável na experiência ( $\mathrm{KrV}$ B 538,539/ A 510,511). Os fatos, portanto, podem ser considerados como produzidos pela liberdade do ser humano, sem que com isso sejam suspensas as leis da natureza ( $\mathrm{KrV}$ B 566,567/A 538,539).

\footnotetext{
${ }^{19}$ Cf. KrV B 560,561/ A 532,533.Ele fala de sentimentos, inclinações e paixões: KrV A 55/ B 79 .

${ }^{20}$ Aqui Kant se afasta decisivamente do conceito de causalidade de Hume. Cf. BARBOSA FILHO B., Sobre uma crítica da razão jurídica, op. cit., p. 20 e ss.

${ }^{21}$ Cf. SALGADO J. C., A idéia de justiça em Kant. Seu fundamento na liberdade e na igualdade, Belo Horizonte: UFMG, 1986.
} 
É neste contexto que Kant vai distinguir a liberdade transcendental da liberdade propriamente prática, que é a liberdade moral e que encontra na liberdade transcendental seu fundamento. Kant define a liberdade transcendental como "a capacidade de começar, por si mesma, um estado cuja causalidade não é subordinada, segundo a lei natural, a uma outra causa que a determinasse de acordo com o tempo" (KrV B 560,561/ A 532,/533). A liberdade prática, por sua vez, é a independência da vontade em relação à coação dos impulsos da sensibilidade, ou seja, às circunstâncias particulares internas ou externas a que está submetido o ser humano enquanto ser de natureza. A liberdade transcendental é, assim, condição de possibilidade da liberdade prática. Essa independência completa da razão em relação à sensibilidade é o que Kant no sentido estrito chama de liberdade (MS AB 6,7), a qual, embora não possa ser conhecida teoricamente, pode, contudo, pelo menos ser pensada.

Neste quadro teórico, a esfera do prático, para Kant, diz respeito, então, a tudo o que é possível através da liberdade. A tarefa específica da Crítica da Razão Prática é, então, o exame do uso prático ${ }^{22}$ da razão, isto é, de seu uso em relação à liberdade ${ }^{23}$. Aqui na autonomia da razão pura prática se situa para ele o único fundamento da normatividade e de seu conhecimento por nós. Na medida em que os conceitos puros da razão são representações que jamais podem ser dadas numa experiência, sua validade objetiva consequentemente não pode ser nem afirmada nem negada pela experiência. Sua realidade objetiva lhes é concedida pela razão prática de tal modo que a razão teórica é obrigada a pressupô-los apesar de não poder conhecê-los.

Que significa isso? Realidade objetiva significa nesse contexto que a liberdade se revela, em última instância, como autoposição ${ }^{24}$. A idéia mesma de liberdade é por princípio inexplicável uma vez que onde não há experiência cessa a possibilidade de explicação. Mas ela se mostra na práxis através da "experiência" da lei moral, pois não se pode tomar consciência da autonomia da vontade sem atinar para uma causalidade que se eleva acima de toda conexão causal da natureza. Neste contexto, Bicca ${ }^{25}$ chama atenção

\footnotetext{
${ }^{22}$ A respeito de objeções ao projeto kantiano cf. ALLISON H. E., Idealism and Freedom, op. cit., p. 158.

${ }^{23}$ A questão central aqui é demonstrar a existência de uma razão pura prática. Kant forneceu esta prova ou pode ele a partir de seu quadro teórico fornecer esta prova? Cf. a respeito: BARBOSA FILHO B., Sobre uma crítica da razão jurídica, op. cit., p. 14 e ss. ${ }^{24}$ Cf. KÖNIG P., Autonomie und Autokratie. Über Kants Metaphysik der Sitten, Berlin/ New York: de Gruyter, 1994.

${ }^{25}$ Cf. BICCA L., A unidade entre ética, política e história na filosofia prática de Kant (primeira parte), in: Filosofia política, 4 (1987) p. 114: "A liberdade positivamente compreendida é pensada como causalidade da razão pura, caracterizando a autodeterminação do sujeito da ação. É isso que começa a ser-nos apresentado desde a Fundamentação da metafísica dos costumes (1785), que o ser humano, o 'único ser racional na Terra', possui por natureza a capacidade de ser seu próprio legislador, onde sua vontade não se submeta a outra regra, além da que ele próprio estabelece”.
} 
ao duplo conceito de liberdade presente na obra de Kant (MS AB 6,7). Liberdade entende Kant em primeiro lugar, num sentido negativo, como independência do determinismo natural. Mas a primazia na obra kantiana se põe numa consideração positiva da liberdade. É precisamente isto que constitui a liberdade, pois em seu cerne ela é a pura posse da razão por si mesma.

Realidade objetiva em relação à liberdade significa exatamente a autoposição dessa nova causalidade ${ }^{26}$ e isto implica em afirmar que unicamente a "forma universal" das máximas pode constituir o fundamento de determinação da vontade uma vez que todo objeto é empiricamente dado. A partir daqui se compreende o caráter estritamente formal da ética kantiana: ele é condição necessária para uma ética autônoma uma vez que todo conteúdo vem da experiência ${ }^{27}$. Sua tarefa consiste em demonstrar aquilo que na esfera da razão prática é objetivamente válido ${ }^{28}$ e por esta razão universalmente obrigatório ${ }^{29}$, capaz de distinguir, portanto, o que é moralmente aceitável do que é moralmente condenável, numa palavra, critérios que possibilitam avaliar a qualidade normativa dos motivos das ações humanas ${ }^{30}$.

Esse uso prático da razão pura tem a ver, portanto, com fins que não provêm dos sentidos, mas única e exclusivamente da razão ${ }^{31}$. A razão prática significa, assim, a liberação do uso empiricamente condicionado da razão

${ }^{26}$ Cf. SANDERMANN E., Die Moral der Vernunft. Transzendentale Handlungs- und Legitimationstheorie in der Philosophie Kants, Freiburg, 1989.

${ }^{27}$ Cf. HÖSLE V., Grösse und Genzen, op. cit., p. 25.

${ }^{28}$ Sobretudo, como diz Kant na Fundamentação da Metafísica dos Costumes, a demonstração do princípio supremo da moralidade, o imperativo categórico, que assim emerge como espécie de ratio cognoscendi de todo tipo de obrigação (GMS BA XIV, XV). Cf. BAUM M., Probleme der Begründung Kantischer Tugendpflichten, in: Jahrbuch für Recht und Ethik, vol. 5 (1997)41-56. HECK J. N., Da Razão prática ao Kant tardio, op. cit., p. 24. Neste livro, Heck defende a tese de que Kant na Metafísica dos Costumes realizou uma ampliação considerável de sua filosofia prática ao acrescentar uma doutrina do direito e uma doutrina das virtudes.

${ }^{29}$ Cf. ALMEIDA G. A. de, Sobre o princípio e a lei universal do Direito em Kant, in Kriterion, n. 114 (2006) 210: “... as leis (práticas) são proposições que apresentam uma ação como objetivamente necessária para todo agente dotado de razão".

${ }^{30}$ Kant distingue claramente dois elementos em toda legislação: o primeiro, o aspecto objetivo, é o que representa ação como o que deve acontecer objetivamente como necessária e o segundo, o aspecto subjetivo, é o que liga subjetivamente a razão de determinação para esta ação com a representação da lei. Cf. MS B 13 e s. Cf. a respeito: VIEIRA L., A herança kantiana da concepção hegeliana do Direito e da Moral, in: Síntese Nova Fase, v. 24 , n. 77 (1997)166 e ss.

${ }^{31}$ Cf. HECK J. N., Da Razão prática ao Kant tardio, op. cit., p. 150: "De acordo com Kant, o suporte do conhecimento normativo é a autonomia da razão pura prática. Os critérios postos à disposição do conhecimento moral e jurídico nascem da razão prática, vale dizer, são idênticos aos traços estruturais da razão". TERRA R., Sobre a arquitetônica da filosofia prática. Passagens: estudo sobre a filosofia de Kant, Rio de Janeiro: Editora UFRJ, 2003, p. 67-84. 
enquanto princípio regulador do conhecimento dos dados fornecidos pela sensibilidade. As leis morais, que são os princípios da razão pura prática, determinam-se completamente a priori. A razão pura prática é, assim, a razão determinando-se unicamente a partir de si mesma, independentemente dos impulsos da sensibilidade ${ }^{32}$. Desta forma, a moralidade das ações humanas consiste precisamente na conformidade das máximas das ações a estas leis universais. Por esta razão o fundamento da obrigatoriedade destas leis não pode para Kant ser encontrado na natureza do ser humano (em nenhuma antropologia) ou nas circunstâncias do mundo, mas unicamente a priori nos conceitos da razão pura (GMS BA VII, IX). Agir moralmente significa consequentemente isto: agir segundo "máximas que prescindem de nossas inclinações e que se qualificam para uma legislação universal" ${ }^{33}$.

Kant interpreta, assim, a transcendência humana como independência prático-moral da espiritualidade em relação à sensibilidade o que de fato significa uma releitura de uma das tendências fundamentais de certas correntes do pensamento metafísico da tradição que é o dualismo entre sensibilidade e razão. Neste contexto a metafísica pretendia ser a "ciência universal" precisamente enquanto transcendência do singular sensível e mutável para o universal, supra-sensível e imutável. Ora, tal dualismo retorna repensado na filosofia de Kant através da diferença entre razão teórica e razão prática. $\mathrm{O}$ universal atingido pelo uso teórico da razão está a serviço do conhecimento do mundo sensível. A razão teórica situa-se na esfera do mundo sensível, mas nele se demonstra, pelo menos, a possibilidade de um mundo supra-sensível (GMS BA 116).

Estas considerações pressupõem de fato uma ontologia dualista, a ontologia do fenômeno e da coisa em si. Com esta ontologia Kant pretende superar a ontologia pressuposta implicitamente pelos cientistas modernos que é incompatível com o "fato moral" uma vez que a existência de uma ética objetiva exige uma ontologia em que haja lugar para valores e normas. Se se deve aceitar a tese de Hume de que não se podem fundamentar sentenças normativas a partir de sentenças descritivas (a falácia naturalista), então nenhum tipo de ontologia naturalista pode constituir o fundamento da ética, o que neste quadro teórico desemboca num dualismo insuperável entre natureza e lei moral ${ }^{34}$.

No nível semântico isto conduz à análise da estrutura própria das sentenças da ética. A tese da falácia naturalista exige que estas sentenças não possam ser sentenças sintéticas a posteriori, pois estas são sentenças empíricas que apresentam fatos. Também não podem ser sentenças analíticas que são senten-

${ }^{32}$ Cf. HECK J. N., Da Razão prática ao Kant tardio, op. cit., p. 30: "A legislação da razão não tem, para Kant, como expressar outra coisa senão ela própria, e também não procura outra coisa senão a si mesma”.

${ }^{33}$ Cf. KLEMME H. F., A discreta antinomia da razão pura prática, op. cit., p.15.

${ }^{34}$ Cf. HÖSLE V., Grösse und Grenzen, op. cit., p.21. 
ças das ciências formais que na concepção de Kant não possuem referência ontológica. Então, as sentenças de uma ética normativa só podem ser sentenças sintéticas a priori e a questão específica de uma filosofia prática consiste em primeiro lugar na fundamentação deste tipo de sentenças.

Sem dúvida, uma das grandes metas de Kant em sua filosofia foi defender a liberdade e, consequentemente com ela, a moralidade dos ataques do mecanicismo naturalista dos cientistas modernos. A solução encontrada foi, então, a distinção da realidade em dois mundos e o ser humano é o lugar do encontro e da unificação desses reinos (GMS BA 117,118). Desta forma, pela vontade racional fazemos parte de uma instância suprassensível, de um reino dos fins, precisamente de um mundo moral em que ocorre a conexão dos seres racionais entre si na medida em que o arbítrio de cada um atua sob o domínio da lei moral, que é uma lei universal criadora de uma unidade sistemática entre todos ( $\mathrm{KrV}$ B 836,837/ A 808,809) ${ }^{35}$. Aqui se explicita uma das teses centrais da filosofia prática de Kant: a qualidade moral de uma ação depende exclusivamente dos motivos que conduzem a vontade.

Quais são, então, no plano da razão prática, os fins supremos da razão pura? Isso se explicita através da consideração da categoria central da filosofia prática de Kant: a autonomia. Com esta categoria, Kant pretende expressar o traço fundamental da vontade boa, a saber, sua indeterminação frente a todos os objetos. Porque ser autônomo, o ser humano se revela como alguém que possui em si mesmo a possibilidade de ser dono de si e consequentemente é livre de toda dependência externa. Nessa perspectiva, a lei moral é a mediação necessária para a determinação da essência do homem que é autodeterminação. Enquanto participa do caráter incondicional da lei moral mostrada no fato da razão essa autonomia é absoluta e enquanto tal concede ao ser humano a dignidade de ser em si mesmo um valor absoluto. A autonomia erradica o ser humano do mecanismo causal universal e o constitui como pessoa, membro do reino moral, reino da liberdade (KpV A 146, 147, 148).

É precisamente enquanto sujeito da lei moral que o ser humano tem valor absoluto, ou seja, enquanto ele é ser livre e é a liberdade que o distingue de todos os outros seres. Por isto o ser humano só obedece a si mesmo. Isto se expressa na fórmula do imperativo categórico: "Age unicamente de acordo com a máxima que faz que tu possas querer assim que ela se torne uma lei universal" (GMS BA 52). Essa formulação geral é explicitada por três outras. Já que Kant chama de "natureza" a existência de objetos enquanto ela é determinada segundo leis universais, então neste caso o imperativo categórico pode ser expresso assim: “Age como se a máxima de tua ação devesse ser instituída por meio de tua vontade como lei universal

\footnotetext{
${ }^{35}$ Em contraposição à interpretação de Hegel, L. Bicca nota que a ideia de reino dos fins em Kant não só implica totalidade, mas também comunidade, isto é, reciprocidade, reconhecimento. Cf. BICCA L., op. cit., p. 125.
} 
da natureza" (GMS BA 52). Só uma máxima que ordena um fim absoluto pode ser estabelecida como lei universal de natureza. Ora, tal fim absoluto só pode ser a vontade do ser racional, pois do contrário não se salva a autonomia. Daí a máxima: "Age de tal maneira que trates a humanidade tanto em tua pessoa como na pessoa de qualquer outro, sempre, ao mesmo tempo, como um fim e nunca simplesmente como um meio" (GMS BA 67).

Isto significa que o ser racional e livre enquanto tal, isto é, como sujeito de moralidade, nunca deve ser usado só como meio e pode usar todas as coisas como meio. Enquanto fim em si mesmo, o ser racional é o autor da legislação universal. A lei moral é válida para todo ser racional, e para um ser puramente racional não vale o imperativo categórico (GMS BA 111, 112,113). No caso do homem, por se tratar de um ser sensível, ela toma a forma de imperativo ${ }^{36}$, isto é, a lei moral incondicional, à medida que entra em relação com as inclinações do homem, assume a forma de imperativo que prescreve incondicionalmente o que deve ser feito ${ }^{37}$.

Considerar, então, o homem como ser livre significa considerá-lo como pertencendo ao mundo inteligível para além de sua inserção no mundo dos fenômenos. É a partir dessa perspectiva teórica que o ser humano se revela como portador de leis puramente racionais e de uma vontade autônoma. A natureza racional põe um fim a si que só pode ser o próprio sujeito racional, enquanto sujeito de todos os fins possíveis. É partir desta concepção que Kant vai fazer sua filosofia moral desembocar na filosofia da história através da concepção de um regime de fins. Kant define o "reino dos fins" como a ligação sistemática de diversos seres racionais por meio de leis comuns. Abstraindo da diferença pessoal dos seres racionais e de todo o conteúdo em seus fins particulares, Kant afirma que é possível pensar um todo enquanto união sistemática de todos os fins. Tal reino só é possível de acordo com os princípios enunciados antes, pois os seres racionais são todos sujeitos à lei segundo a qual cada um deles nunca deve tratar a si mesmo e aos outros simplesmente como meio, mas sempre, ao mesmo tempo, como fim em si mesmo ${ }^{38}$.

\footnotetext{
${ }^{36}$ Cf. ALMEIDA G. A. de, Sobre o princípio e a lei universal do Direito em Kant, op. cit., p. 211: “... Kant formula essa "lei universal do Direito" como um imperativo, que é a forma pela qual as leis práticas se apresentam a uma arbítrio imperfeitamente racional". ${ }^{37} \mathrm{E}$ a partir daqui que se pode justamente falar de uma discreta antinomia da razão pura prática. A respeito da diferença desta antinomia para com as antinomias da Crítica da Razão Pura, Cf. KLEMME H. F., A discreta antinomia da razão pura prática, op. cit., p. 23-29.

${ }^{38}$ GMS BA 74,75. HERRERO X., Teoria da história em Kant, in: Síntese 22 (1981), 31: "Nenhuma justificação histórica poderá substituir, para Kant, o princípio da razão, a saber, o princípio do direito, que contém a exigência incondicionada de usar a humanidade, na pessoa de cada indivíduo, sempre como fim e nunca como meio. Pelo contrário, é este princípio que julga toda pretensão de favorecer minorias com prejuízo do povo ou de sacrificar o indivíduo em favor da sociedade futura".
} 


\section{2) O Lugar do Direito na História humana}

Esse reino dos fins enquanto unidade última de todos os seres racionais é um reino de liberdade e, por conseguinte, pertence ao mundo inteligível. O problema central que surge neste contexto na filosofia de Kant é saber como ocorre o trânsito entre o mundo inteligível e o mundo sensível, isto é, entre liberdade e natureza. Já que a lei moral, no caso específico do ser humano, adota a forma de um imperativo categórico, visto que ele sendo também um ser de natureza é imperfeitamente racional, a determinação da vontade possui aqui uma tarefa positiva própria: configurar o mundo sensível de acordo com a lei moral na obediência às suas leis. Isto implica dizer que os princípios do direito são subordinados aos princípios morais, porque "o imperativo moral é um imperativo incondicional ${ }^{39 "}$ ". O que está em jogo aqui, portanto, é uma intervenção no mundo, que é estruturado pelas leis naturais, a partir das leis da liberdade. Kant afirma que o mundo sensível deve conter a imagem do mundo inteligível, da lei moral (KpV A 74,75,76). Ora, isso significa que Kant está aqui abrindo perspectivas para a vida humana concreta, sua vida histórica. Então, nesse caso, a história revela-se como a possível configuração do mundo fenomenal pela razão, pela lei moral ${ }^{40}$.

No mundo moral, os homens constituem, assim, um todo o que significa que a liberdade encontra sua efetivação suprema na esfera da sociabilida$\mathrm{de}^{41}$. Mas justamente aqui aflora o conflito na vida humana, pois uns podem assumir a lei moral, outros não. $O$ crescimento de ações externas opostas à lei vai criando uma atmosfera negativa que acaba repercutindo na vida dos indivíduos. Daqui brota um desafio básico: o ser humano, enquanto ser também sensível, só chegará à efetivação como ser de razão se conseguir exteriorizar sua liberdade interna no mundo sensível o que se configura precisamente como a unificação de liberdade e natureza. Kant

\footnotetext{
${ }^{39}$ ALMEIDA G. A. de, Sobre o princípio e a lei universal do Direito em Kant, op. cit., p 215. A tese que Almeida procura demonstrar aqui é que os princípios do direito são concebidos por Kant não apenas como subordinados, mas como derivados do imperativo moral o que para ele não destroi a diferença entre moral e direito. Cf. p. 216 e ss.

${ }^{40}$ Para Marques a esfera do político constitui uma dimensão específica da normatividade que combina a normatividade ética e a normatividade jurídica e por isto deve ser distinguida tanto da ética como do direito. Cf. MARQUES A., O Estado de Direito do ponto de vista de uma faculdade de julgar política, in: PERES T. D. e outros (orgs.), op. cit., p. 152-153.

${ }^{41}$ Uma questão básica neste contexto é o conceito de sociedade em Kant Cf. MARQUES A., O Estado de Direito do ponto de vista de uma faculdade de julgar política, op. cit., p. 147: "Esta não é, na sua perspectiva, um organismo nem natural, nem de segunda ordem, que inevitavelmente tende ou se dirige para um determinado estádio, mas sim um conjunto de indivíduos que procuram satisfazer as suas necessidades naturais e que possuem a capacidade de resolver racionalmente os conflitos resultantes da dessas necessidades. É dessa necessidade de solução racional de conflitos que nasce o estado jurídico como um plano superior de evolução da humanidade, a qual abandona um status naturalis, o qual, precisamente por não ser jurídico, é essencialmente injusto".
} 
denomina legalidade justamente esta realização da liberdade na esfera da exterioridade que é a esfera do direito ${ }^{42}$. Desta forma o direito em seu cerne consiste na unificação de liberdade e natureza e tem a ver com o mundo externo em que se estabelecem relações recíprocas entre os seres humanos. Por isso ele é a lei universal "pela qual prescrevo a mim os mesmos deveres que imponho a todos os demais ${ }^{43 \prime}$. Trata-se fundamentalmente aqui da liberdade do arbítrio na medida em que ela pode coexistir com a liberdade de todos segundo uma lei universal (MS I, A34, B 35). Portanto, neste contexto se faz possível compreender o papel fundamental do direito na vida humana ${ }^{44}$ : suas leis exigem com coerção por razões morais aquilo que pode ser exigido moralmente de todos, portanto "o exigem também daqueles que, embora saibam o que a lei moral exige deles, não querem se conformar a ela, e só o fazem sob a condição de seu interesse privado, ou se forem coagidos a isso (e é nesse sentido que elas constituem uma subclasse das leis morais)" ${ }^{\prime 4}$.

Este é para Kant o "princípio universal do direito", tanto para o direito privado como para o direito público, e é por esta razão fundamental que o direito desconsidera as intenções dos agentes, tendo a ver única e exclusivamente com a forma das relações recíprocas e sua compatibilidade com leis universais, ou seja, ele diz respeito às ações externas dos indivíduos na medida em que elas afetam as ações dos outros indivíduos enquanto ações que provêm de seus arbítrios e desta forma se distingue da ética. Assim, o direito se situa nas relações entre arbítrios. É o que constitui para Kant propriamente a história política da humanidade, a qual deve ser pensada no horizonte do conflito entre a natureza como fenômeno e os efeitos da liberdade como fenômenos no mundo.

Tal problemática levanta uma questão central na filosofia de Kant: existe um fundamento comum aos fenômenos da natureza e aos efeitos fenomenais da liberdade? Como pensar a instância de mediação entre a esfera da natureza e a esfera da liberdade? É precisamente esta a questão trabalhada pela Crítica do Juízo que para Kant possui a tarefa enorme de efetivar de forma conclusiva o projeto de uma crítica da razão através da razão, que constitui a pretensão de sua filosofia (KU B V, VI, A V, VI) ${ }^{46}$. Kant pensa

${ }^{42}$ Cf. HECK J. N., Direito e Lei em I. Kant, in: Síntese Nova Fase, vol. XXV, n. 80 (1998) 43-72.

${ }^{43}$ Cf. HECK J.N., Da Razão prática ao Kant tardio, op. cit., , p.101.

${ }^{44}$ A respeito da influência da filosofia de Kant no pensamento contemporâneo cf. HECK J. N., As recepções de Tugendhat e Habermas da doutrina kantiana do Direito, in: Sintese Nova Fase, vol. 27, n. 89 (2000) 349-374.

${ }_{45}$ ALMEIDA G. A. de, Sobre o princípio e a lei universal do Direito em Kant, op. cit., p 217-218.

${ }^{46}$ Cf. SCHMIED-KOWARZIK W., "Von der wirklichen, von der seyenden Natur". Schellings Ringen um eine Natrurphilosophie in Auseinandersetzung mit Kant, Fichte und Hegel, Stuttgart/ Bad Cannstatt: Fromman-Holzboog, 1996, p. 38-39. 
essa problemática através da mediação da teleologia, objeto do juízo de finalidade que é para ele enquanto princípio da finalidade da natureza em sua multiplicidade e do mútuo pertencer de suas formações um princípio subjetivo (uma máxima) da força de juízo (KU B XXXIV, A XXXII) sem o qual seria impossível pensar uma conexão completa dos conhecimentos empíricos num todo da experiência (KU XXXIII, A XXXI) e assim atingir o objetivo final de todo conhecimento. É justamente o conceito de "finalidade da natureza" que possibilita a passagem da razão puramente teórica à razão puramente prática, pois desta forma é reconhecida a possibilidade do fim supremo, que se pode realizar na natureza de acordo com suas leis. Para Kant, é precisamente o conceito de matéria enquanto algo organizado que nos conduz ao conceito de fim natural, que, por sua vez, nos leva à ideia de que a natureza inteira é um sistema segundo as regras dos fins.

Esse princípio torna possível um outro relacionamento entre o ser humano e a natureza, permitindo um conhecimento especial da natureza que possibilita pensar a efetivação da mediação entre natureza e liberdade ${ }^{47}$. Ele articula um conceito teleológico do mundo e isto permite concebê-lo como um "todo coerente segundo fins" (KU B 413). Nesta perspectiva, todo particular, todo fortuito ou contingente, é ordenado segundo um todo final. Para alcançar finalidade na natureza se faz necessário considerar o todo real como "fim natural". É nos seres vivos da natureza que Kant apresenta uma finalidade que servirá de paradigma a toda finalidade no mundo. Ora, a característica própria do ser vivo é a exibição de ordem e organização em seus elementos constitutivos. Para poder ser pensado como fim natural o ser vivo tem de ser, então, causa e efeito em si mesmo: o todo o precede como fundamento de sua existência e de sua forma. Cada parte é pensada como órgão produtor de todas as outras.

Portanto, é a "natureza interna" que agora é vista como sistema teleo1ógico organizado, pois a finalidade interna de um organismo exige também a finalidade externa de outras entidades. Nesse caso, podemos encontrar uma sucessão indefinida de fins, que para nada serviria se não pudéssemos encontrar um fim último, que enquanto tal (KU B 282) constitui a condição de possibilidade interna de um sistema teleológico como ponto que dá sentido a todos os fins relativos, os quais, desta forma, se manifestam como meios para o fim último. Existe unicamente um tipo de ser no mundo que é portador de uma causalidade teleológica, orientada a fins: o ser humano é exatamente o ser dessa espécie, porém o ser humano considerado como ser "numenal".

O ser humano é o único ser da natureza em quem podemos reconhecer, em virtude de sua própria constituição, um poder suprassensível - a

${ }^{47}$ Cf. BORGES M. L./ HECK J. N. (org.), Kant: liberdade e natureza, Florianópolis: Ed. da UFSC, 2005. 
liberdade -, e mesmo a lei da causalidade e seu objeto que ele se pode propor como fim supremo. Por que existe o ser humano como ser moral? Justamente porque enquanto ser moral ele contém em si o fim supremo, ao qual, na medida de suas forças, o ser humano pode submeter toda a natureza. Sem o ser humano enquanto fim supremo da natureza (KU B 398) seria impossível estabelecer a cadeia dos fins subordinados uns aos outros. Só no ser humano enquanto ser moral podemos alcançar a legislação incondicionada relativamente aos fins, que faz dele o fim supremo a que se subordina toda a natureza.

Exatamente nisto se concentra o objetivo central da filosofia da história de Kant: pensar a história é pensar a totalidade como mediação entre teoria e práxis. A história é o processo teleológico através do qual a lei moral, enquanto pura exigência inteligível, toma posse pouco a pouco do ser humano como ser empírico (fenomenal) ${ }^{48}$. Nesse sentido, a história é um processo de espiritualização, de moralização da realidade empírica humana, através de que a humanidade se constitui progressivamente sob a forma de uma sociedade organizada segundo a lei, como corpo visível da liberdade. Nesta perspectiva, o problema fundamental da humanidade considerada em sua totalidade é a criação de uma sociedade civil que possa gerir o direito de forma universal ${ }^{49}$, porque não há outra maneira de cercear a violência, restringir suas consequências danosas na existência humana e assegurar uma paz universal e duradoura. A consecução deste objetivo pressupõe que se resolva via legislação a questão da posse privada de bens.

O que está em jogo aqui, em última instância, é a configuração de uma forma de vida em que seja possível compatibilizar, de um lado, a mais radical autonomia do individuo, do outro, a seu caráter social. Trata-se, portanto, de estabelecer padrões mínimos de convivência o que implica a criação de instituições que possam assegurar a eficiência normativa. A natureza se serve justamente da contraposição entre essas duas dimensões do ser humano (a sociabilidade insociável, na expressão de Kant) para lhe impor esta conciliação e produzir um estado generalizado de segurança

${ }^{48}$ Cf. HERRERO X.,, Teoria da história em Kant, op. cit., p. 20: "Mas o homem se diferencia de todos os outros por estar dotado de disposições que 'visam o uso da razão' (11). Assim, a história do gênero humano começa com o estado natural. Mas sua meta é a conquista da razão sobre o irracional, e está pois na sua infinitude. Então, o desenvolvimento da história, segundo as três disposições naturais, passa por três etapas: a aculturação, a civilização e a moralização dos homens na história. Por este caminho, a disposição moral se libertará aos poucos da coação natural dos impulsos e se tornará possível a eticidade como livre autodeterminação da vontade pela lei moral".

${ }^{49}$ Cf. KANT I., "Idee zu einer allgemeinen Geschichte in weltbürgerlicher Absicht", A 395. BATSCHA Z. (org.), Materialien zu Kants Rechtsphilosophie, Frankfurt am Main: Suhrkamp, 1986. 
pública. Desta forma, pode-se afirmar, com E. Weil ${ }^{50}$, que em Kant o ser humano só é verdadeiramente humano pela mediação da natureza uma vez que é a teleologia da natureza que atesta como esse ser natural tem condições de atingir o que excede a própria natureza. É isto precisamente o que constitui a ambiguidade fundamental da vida humana ${ }^{51}$.

A lei neste sentido se revela como uma espécie de materialização sempre deficiente da moral de tal modo que se deve considerar a sociedade civil como a aproximação do reino dos fins ${ }^{52}$ já que a legislação produz uma situação em que a efetivação da liberdade humana se faz possível ${ }^{53}$. No entanto, para Kant a realização da liberdade é exclusivamente fruto de uma opção pessoal frente à interpelação do incondicionado. Ninguém pode nem deve tentar forçar pessoa alguma a isso. O que é possível fazer é exatamente aquilo que já faz o processo teleológico, ou seja, produzir os pressupostos necessários para a efetivação da liberdade.

É a partir daqui que Kant compreende o Estado moderno precisamente como uma sociedade civil que gere universalmente o direito o que o leva a concluir que a questão da virtude (da moral) não pode ser um problema do Estado ${ }^{54}$; nesse sentido, o Estado moderno ${ }^{55}$ se funda na lei universal

${ }^{50}$ Cf. WEIL E., Problèmes Kantiens, 2 ${ }^{\mathrm{a}}$. ed., Paris, 1970, p. 85. PERINE M., Filosofia e violência, sentido e intenção da filosofia de Eric Weil, São Paulo: Loyola, 1987, p. 66ss. ${ }^{51}$ Cf. BICCA L., A unidade entre ética, política e história na filosofia prática de Kant (segunda parte), op. cit., p. 30: "Depreende-se da passagem citada que uma ambivalência fundamental localiza-se já na natureza humana: o ser humano tanto tem o impulso ou a inclinação espontânea para associar-se quanto para isolar-se, destacar-se dos demais seres ou agrupamentos humanos. Ora, aqui Kant está afirmando que a sociabilidade é tão natural quanto a insociabilidade, ou, dito apenas de outra maneira, que a natureza do homem compõe-se de ambos os momentos, sendo, na verdade, sua unidade (com isso, apenas para anotar, Kant dá um passo importante em termos da preparação da tentativa de 'suprassunção' (Aufhebung) do moderno individualismo, que terá lugar na filosofia de Hegel, por já esquematizar o que seria a síntese de um elemento de fundação antropológica das concepções ético-políticas da tradição do direito natural moderno com o significado mais corriqueiro do conceito de zoon politikon da eticidade greco-clássica)". Cf. também GIANNOTTI J. A., Kant e o espaço da história universal, in: Discurso, 10 (1979), 7-48, sobretudo 31ss.

${ }^{52}$ Cf.. GIANNOTTI J. A., op. cit., p. 23: "Como se vê, Kant não distingue Estado de sociedade civil, ambos designando a esfera de sociabilidade que imprime a todas as outras relações sociais o cunho da legalidade. O Estado é o escopo desenhado pela moralidade, delimitando a liberdade de cada um, a fim de permitir que ela se efetue coletivamente".

${ }^{53}$ Cf. RENAUT A./SOSOE L., Philosophie du droit, Paris: PUF, 1991.

${ }^{54}$ Cf. KERSTING W., Recht, Gerechtigkeit und demokratische Tugend. Abhandlungen zur praktischen Philosophie der Gegenwart, Frankfurt am Main: Suhrkamp, 1997, p. 106.

${ }^{55}$ Cf. GOYARD-FABRE S., La philosophie du droit de Kant, Paris: Vrin, 1996. HÜNING D./ TUSCHLING B. (org.), Recht, Staat und Völkerrecht bei I. Kant, Berlin: Duncker \& Humblot, 1998. BOBBIO N., Direito e Estado no pensamento de Emanuel Kant, $2^{\underline{a}}$. Ed. Brasília: Ed. UNB, 1999. GOMES A., O fundamento de validade do direito: Kant $e$ Kelsen, Belo Horizonte: Mandamentos, 2000. 
que assegura a liberdade de cada integrante da sociedade, a igualdade de todos sob a lei e a independência de cada um como participante de um ser $\operatorname{comunitário}^{56}$. Sua legitimidade, portanto, se radica no respeito à liberda$\mathrm{de}^{57}$.

O Estado é, assim, o sistema de instituições políticas e de funções de poder, cuja necessidade é inerente ao direito na medida em que ele é condição de possibilidade de sua eficácia. Conseqüentemente sua criação constitui um dever já que enquanto ser racional o ser humano deve superar qualquer tipo de violência e configurar suas relações sociais de acordo com as regras do direito. Assim, para Kant há uma contraposição radical entre o estado de natureza (estado da violência recíproca) e o estado jurídico (estado da razão $)^{58}$, que então se revela como estado da liberdade. Esse estado nada tem a ver com a polis de Aristóteles: seu objetivo agora é assegurar a vida, a propriedade e a ordem ética de seus cidadãos. Por esta razão, para Kant, o que caracteriza fundamentalmente as instituições do Estado moderno é ser o penhor da liberdade, da igualdade e da autonomia dos cidadãos ${ }^{59}$.

A teoria de Kant tem raízes antropológicas: se por um lado, o ser humano só pode obedecer a sua lei interna, por outro, a liberdade só pode existir na esfera da comunhão dos seres livres. Portanto, a condição de possibilidade da coexistência de seres racionais e livres é que estes se submetam à lei universal da liberdade que justamente por esta razão constitui o fundamento da coerção ${ }^{60}$. Dessa lei derivam todos os direitos e deveres do ser humano e seu direito básico é precisamente este: coexistir com todos os outros sob uma lei universal. Nisso consiste essencialmente o direito, ou seja, em ser o conjunto das condições sob as quais o arbítrio de um pode ser conciliado com o arbítrio do outro, segundo uma lei universal (MS A

\footnotetext{
${ }^{56}$ Por esta razão, afirma Kersting, sem o Estado não haveria efetivação do direito racional. Cf. KERSTING W., Vernunftecht, Gerechtigkeit und Rechtsverbindlichkeit, mimeo, Porto Alegre, 2003, p. 8.

${ }^{57}$ Cf. HECK J. N., Da Razão prática ao Kant tardio, op. cit., , p. 178.

${ }^{58}$ Kant repensa tradição moderna do pensamento político que tinha a categoria de contrato como categoria central na medida em que pensa o contrato como uma idéia prática da razão. Cf. HECK J. N., Da Razão prática ao Kant tardio, op. cit., p. 178: “.... sua justificação da autoridade estatal por meio da dedução da idéias de um contrato social rompe as bases argumentativas da tradição contratualista, na medida em que nela se remete, direta ou indiretamente, à natureza humana ou se apresenta uma imaginada reconstrução de dados empíricos ou semi-empíricos".

${ }^{59}$ Cf. BICCA L., "A unidade entre ética, política e história na filosofia política kantiana" (segunda parte), op. cit., p. 27ss. HABERMAS J., Kants Idee des ewigen Friedens _aus dem historischen Abstand von 200 Jahren, in: Die Einbeziehung des Anderen. Studien zur politischen Theorie, Frankfurt am Main: Suhrkamp, p. 192-236.

${ }^{60}$ Cf. HECK J. N., Da Razão prática ao Kant tardio, op. cit., p. 92: "Para o juspositivista Kelsen, o direito positivo identifica salteadores que se tornam Estado. O jusfilósofo Kant resiste, por sua vez, à tentação de moralizar a violência na fundação da soberania política, Para ambos os doutrinadores, todo direito tem historicamente por base um ato de força, sob o qual está erguido o respectivo império da lei”.
} 
33/B 33,34). Desta forma, a liberdade externa só se pode efetivar sob a forma de direito.

O direito não diz respeito ao fim que cada um pode propor-se, ou seja, aos motivos que movem a ação humana, mas à forma de coexistência dos arbítrios segundo uma lei universal, ou seja, à forma das relações intersubjetivas ${ }^{61}$. Desta forma, ele constitui uma forma simétrica de relações entre seres livres e iguais e por esta razão rejeita toda forma de limitação da liberdade que não se conceba como juridicamente correlata à liberdade dos outros. Daí porque o direito de humanidade kantiano "habilita cada ser humano a submeter a conduta de seus semelhantes à lei geral do direito e, à luz dessa vinculação, capacita o homem a limitar o agir desenfreado dos outros pelo uso pleno da própria liberdade"62.

Através do direito se estabelece, então, uma legislação universal para a garantia da liberdade do agente juntamente com a liberdade dos outros, portanto, para a garantia da liberdade de todos. Justamente aqui se manifesta a superioridade do direito em relação à ética porque o direito vincula lei e ação enquanto que a ética apenas fornece leis para as máximas das ações sem prescrever os meios de sua efetivação. Nessa perspectiva, o direito se constitui como a instância de universalização do indivíduo na esfera da exterioridade. Ele deixa de ser simplesmente coação para tornarse efetivação da liberdade. É precisamente isso que afasta Kant de qualquer positivismo do direito ${ }^{63}$ uma vez que se trata aqui de fornecer os princípios imutáveis que constituem o fundamento de uma possível legislação positiva, ou seja, de estabelecer o critério universal a partir de onde se possa saber o que justo ou injusto. $\mathrm{O}$ positivismo, considerado a partir de Kant, consiste na identificação pura e simples de fato e direito pelo menos no sentido de que ele pressupõe que as normas individuais do direito se originam de atos de vontade ligados a uma norma superior estabelecida $^{64}$ sem que esta norma tenha outra fundamentação além do arbítrio de quem a estabelece.

Há, portanto, uma teleologia histórica, que se insere numa teleologia da natureza, criando uma ordem que vai expressar na natureza as exigências do espírito, e isto é precisamente, na expressão de Kant, a sociedade jurí-

\footnotetext{
${ }^{61}$ Cf. HECK J. N., Da Razão prática ao Kant tardio, op. cit., p. 78: "O objeto de todo dever de direito é uma ação à qual um indivíduo pode ser obrigado por outro, com vistas ao direito subjetivo que cabe ao último, com base na leio geral do direito".

${ }^{62}$ Cf. HECK J. N., Da Razão prática ao Kant tardio, op. cit., p. 107.

${ }^{63}$ Cf. REISINGER P., "Der eleutherologische Rechtsbegriff. Kant, das Grund- gesetz und die Aporien im Positivismus und in materialen Wertlehren” in: Phil. Jahrbuch, 96 (1989), 294-313. TERRA R. R., "A distinção entre direito e ética na filosofia kantiana", in: Filosofia política 4 (1987), 49-65.

${ }^{64}$ Cf. KELSEN H., Reine Rechtslehre, 2ª ${ }^{\mathrm{a}}$ Ed., Wien: Franz Deutike, 1960.
} 
dico-civil ${ }^{65}$. Essa sociedade civil, enquanto subordinação de toda a história à razão prática, pode evocar a possibilidade da unidade do fundamento suprassensível da natureza e da liberdade. Nesse sentido, a política, para Kant, não é a suprema realização do ser humano, mas tem apenas a tarefa de criar as condições de possibilidade de sua realização como ser racional, o que só pode ocorrer na esfera da moralidade ${ }^{66}$. Isso se dá à medida que todas as ações sociais se submetem incondicionalmente a algo coletivo, por uma coisa pública que é a "constituição civil", o que transforma os indivíduos em cidadãos.

Endereço do Autor:

Rua Catão Mamede, 218 - Apto. 603

60140-110 Fortaleza - CE

manfredo.oliveira@uol.com.br

${ }^{65}$ HERRERO F. J., op. cit., p. 163: "Esa sociedad sólo podrá posibilitar Ia realización de Ia libertad de todos por leyes externas si es regida por una Constitución civil justa que sea Ia expresión de una voluntad pública, fuente de todo derecho y exclusión de toda injusticia”.

${ }^{66}$ HERRERO F. X., A teoria da história em Kant, op. cit., p. 27: "A grande tarefa que finalmente a natureza impõe ao homem é que ele, como ser racional, arranque da natureza a direção da história para assumi-la responsavelmente em suas próprias mãos e, assim, construindo ele mesmo, consciente e livremente, uma sociedade política estruturada segundo os princípios morais da justiça e da liberdade, possa conseguir o seu fim último que é 'a humanidade (o ser racional do mundo) na sua completa perfeição moral.” 